\title{
Laves Phase Formation and Its Effect on Mechanical Properties in P91 Steel
}

\author{
Zhi-Xin Xia ${ }^{1} \cdot$ Chuan-Yang Wang ${ }^{2} \cdot{\text { Yan-Fen } Z^{2}{ }^{3}}^{3}$ Guo-Dong Zhang ${ }^{3} \cdot$ Lu Zhang $^{3} \cdot$ Xin-Ming Meng $^{3}$
}

Received: 25 June 2015/Revised: 13 August 2015/Published online: 25 September 2015

(C) The Chinese Society for Metals and Springer-Verlag Berlin Heidelberg 2015

\begin{abstract}
Effect of Laves phase formation on mechanical properties in a pressurized T-junction of P91 steel pipe at $849 \mathrm{~K}$ for $58,000 \mathrm{~h}$ with $25.65 \mathrm{MPa}$ vapor pressure was studied. Thermodynamic calculations had been performed by using the software Thermo-Calc to study the phase at equilibrium state. Counter plot of von Mises stress in the pipe during service life was calculated by finite element analysis to study the effect of the operated stress distribution on the evolution of Laves phase. The change in the microstructure and mechanical properties in the sites with different stress was also studied. The results indicated that the formation of Laves phase in $\mathrm{P} 91$ steel was a thermodynamically possible process due to enrichment of Mo and depletion of $\mathrm{C}$ adjacent to $M_{23} \mathrm{C}_{6}$ particles or along martensite lath and packet boundaries. The formation of Laves phase had a detrimental influence on the mechanical properties in P91 steel. The mean size of Laves phase would be significantly increased with increasing operated stress, leading to a reduction in tensile properties and impact energy. In particular, crack initiation energy and crack growth energy during impact test rapidly decreased with increasing the mean size and volume fraction of Laves phase.
\end{abstract}

KEY WORDS: Heat-resistant steels; Laves phase; Creep; Precipitation; Phase stability

\section{Introduction}

Nine percentage $\mathrm{Cr}$ ferritic heat-resistant steels have been developed for the boiler and turbine of a supercritical power plant [1]. There is a strong requirement for prevention of a decrease in the mechanical properties caused by a change in microstructure. $M_{23} \mathrm{C}_{6}$ and $M X(M=\mathrm{V}, \mathrm{Nb}$,

Available online at http://link.springer.com/journal/40195

Zhi-Xin Xia

xiazhixin2000@163.com

1 Shagang School of Iron and Steel, Soochow University, Suzhou 215021, China

2 School of Mechanical and Electric Engineering, Soochow University, Suzhou 215021, China

3 Suzhou Nuclear Power Research Institute, Suzhou 215004, China
$X=\mathrm{C}, \mathrm{N})$ are mentioned as dominant precipitates in tempered martensite, and $M_{23} \mathrm{C}_{6}$ carbides mainly precipitate along prior austenite grain boundaries and martensite packet boundaries [2]. The agglomeration of coarse $M_{23} \mathrm{C}_{6}$ and Laves phase would reduce mechanical properties such as creep resistance and impact toughness in $9 \mathrm{Cr}$ heat-resistant steels [3, 4]. Another potential precipitate is Laves phase in heat-resistant steels during high-temperature exposure, which has drawn a growing interest for the enhancement of creep strength [5-7]. Laves phase is a compound of A2B type with topologically close-packed (TCP) structure and is expected to have high-temperature strength. The fine Laves phase precipitates on the packet boundaries and the grain boundaries that could retard the recovery of sub-grains, so that it improves the creep strength at high temperature [1]. However, other authors suggest that the formation of Laves phase is detrimental to the creep properties in $\mathrm{P} 92$ steel, mainly because the precipitation of $\mathrm{Fe}_{2} \mathrm{~W}$ Laves phase promotes depletion of $\mathrm{W}$ 
from solid solution, and most of creep cavities are nucleated at coarse Laves phase particles on the grain boundaries [8]. Therefore, control of Laves phase precipitation behavior should be an important method to achieve an excellent creep resistance in heat-resistant steel [9]. At present, the quantification of Laves phase in (9-12) wt $\% \mathrm{Cr}$ ferritic heat-resistant steels using a SEM with backscattered electron is assumed to be sound [10]. It makes the study about effect of Laves phase on mechanical properties convenient. The formation and dissolution behaviors of Laves phase were studied in P91 steel [11], and the rate of formation of $\mathrm{Fe}_{2} \mathrm{Mo}$ Laves phase depended on the diffusion of molybdenum to precipitation sites. Two mechanisms for the nucleation and growth of Laves phase have been proposed $[5,12,13]$. Laves phase precipitates in Cr-depleted regions adjacent to $M_{23} \mathrm{C}_{6}$ carbides or on the martensite packet and the grain boundaries without the presence of $M_{23} \mathrm{C}_{6}$ carbide in the vicinity, because the high $\mathrm{W}$ and $\mathrm{Mo}$ contents in such regions are beneficial to the formation of Laves phase. The formation of Laves phase will deteriorate the creep properties [14] and impact toughness [15] in P91 steel. However, the others report that Laves phase has not

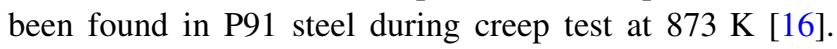
The formation of Laves phase is a thermodynamically impossible process in $\mathrm{P} 91$ steel with $9 \mathrm{Cr}-1 \mathrm{Mo}$ according to thermodynamic calculations at $849 \mathrm{~K}$. The reason of formation of Laves phase is still beyond understanding. This is a relevant practical study of phase transformations occurring in the pressurized T-junction of $\mathrm{P} 91$ steel pipe during service. The microstructure of different sites is sensitive to the operated stress in the T-junction. Fortunately, we observed Laves phase particles in the T-junction. It is the aim of this work to further gain systematic understanding of Laves phase formation mechanism and its effect on mechanical properties in P91 steel.

\section{Materials and Experimental Methods}

A pressurized T-junction of $\mathrm{P} 91$ steel pipe was produced by hot extruding and shaping apparatus, which consists of $\Phi 571.5 \mathrm{~mm} \times 84 \mathrm{~mm}$ A-pipe and $\Phi 540 \mathrm{~mm} \times 80 \mathrm{~mm}$ B-pipe, as shown in Fig. 1a. Then, it was kept at $849 \mathrm{~K}$ for $58,000 \mathrm{~h}$ with $25.65 \mathrm{MPa}$ vapor pressure. The operated stress is analyzed by finite element software ABAQUS codes, and its version is 6.10. For the finite element model, the pipe $\mathrm{A}$ is carried on clamped boundary conditions, and the pipe B is carried on simply supported boundary conditions as shown in Fig. 1b. Inner pressure is loaded on the pipe $\mathrm{A}$, and considering the pipe $\mathrm{B}$ also subjected to inner pressure, the axial stress will be loaded on the pipe B. Physical properties of P91 steel were provided such as density $7780 \mathrm{~kg} / \mathrm{m}^{3}$; thermal expansion coefficient
$12.35 \times 10^{-6} / \mathrm{K}$; elastic modulus $1.75 \times 10^{5} \mathrm{MPa}$; Poisson's ratio 0.29 ; creep coefficient, $B, 9.016 \times 10^{-27}$; and creep exponent, $n, 10.286$. Load of finite element analysis is given in Fig. 1c. Based on finite element analysis, the distribution of von Mises stress in the T-junction is shown in Fig. 1d. The maximum operated stress happens to the shoulder of T-junction (the site A). The operated stress from inner wall to outer wall of the site A decreased from 85.5 to $73.5 \mathrm{MPa}$. Correspondingly, the operated stress from inner wall to outer wall of the site B decreased from 66.8 to $61.1 \mathrm{MPa}$. The specimens were taken from the sites $\mathrm{A}$ and $\mathrm{B}$ in Fig. 1a, respectively (designated specimen A and specimen $\mathrm{B}$ ).

The chemical compositions of the specimen A and B are listed in Table 1. Mechanical properties were calculated by averaging the value from inner, middle and outer wall of the T-junction. Tensile properties such as yield strength, ultimate strength at room temperature and $849 \mathrm{~K}$ were tested. The longitudinal tensile specimens with a gage diameter of $5 \mathrm{~mm}$ and a gage length of $25 \mathrm{~mm}$ were used. All tensile tests were performed at room temperature at a crosshead speed of $0.5 \mathrm{~mm} / \mathrm{min}$, and each tensile property was calculated by averaging the values of three specimens. The V-notch impact specimens with dimension of $10 \mathrm{~mm} \times 10 \mathrm{~mm} \times 55 \mathrm{~mm}$ for the longitudinal orientation and transverse orientation were used, respectively. The V-notch impact tests were carried out on a standard impact machine at $293 \mathrm{~K}$, and the impact absorption energy was calculated by averaging the value from three specimens. After the tests, the microstructures were observed by optical microscope, SEM and TEM. The kinds and compositions of typical precipitates in these specimens were identified by SEM with BSE and TEM with EDS. The volume fractions of the precipitated particles were determined by linear intercept method. Thermodynamic calculations were performed using the software Thermo-Calc with database SSOL5.

\section{Results and Discussion}

\subsection{Thermodynamic Calculations of Laves Phase Formation}

$M X(M=\mathrm{V}, \mathrm{Nb} ; X=\mathrm{C}, \mathrm{N})$ starts to precipitate at above $1553 \mathrm{~K}$ [18], and $M X$ will always be considered to remain in P91 steel. Therefore, the changes in $M_{23} \mathrm{C}_{6}$ and Laves mainly are considered in thermodynamic calculations. The formation of Laves phase is a thermodynamically impossible process in P91 steel according to thermodynamic calculations at equilibrium state of $849 \mathrm{~K}$. Thermo-Calc calculations of the phase diagram for P91 steel are shown in Fig. 2a. Change in phases was related to temperature and 

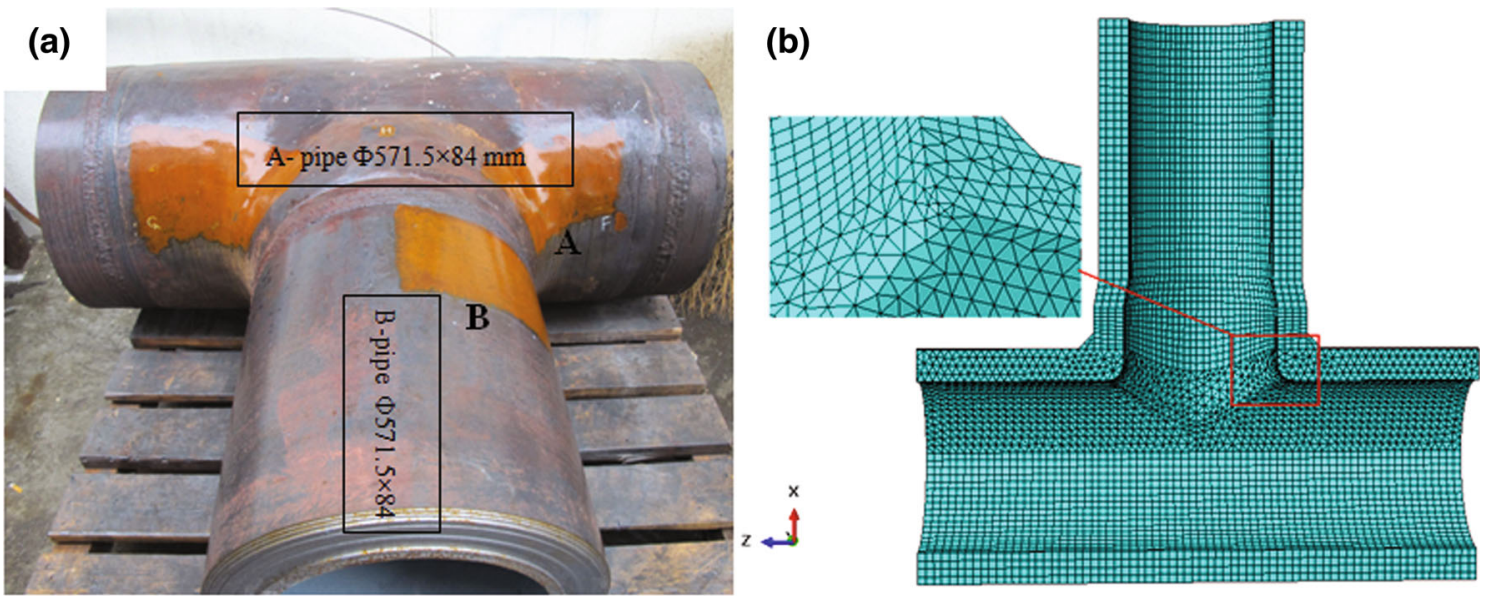

(c)

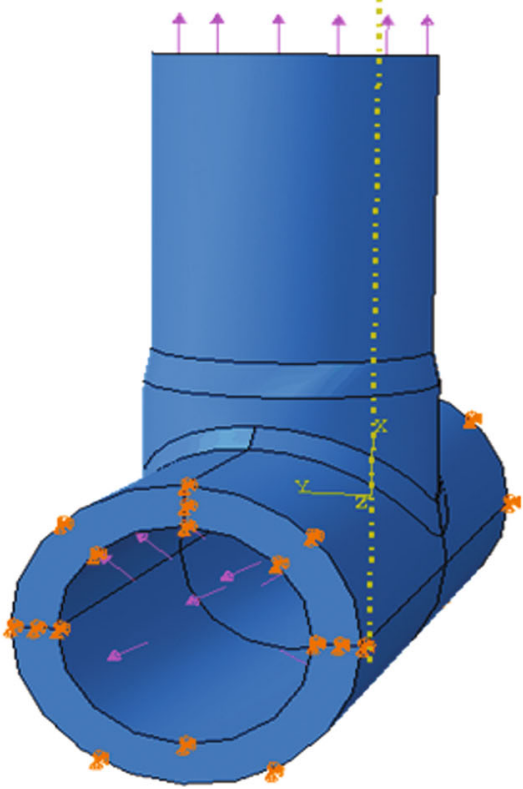

(d)

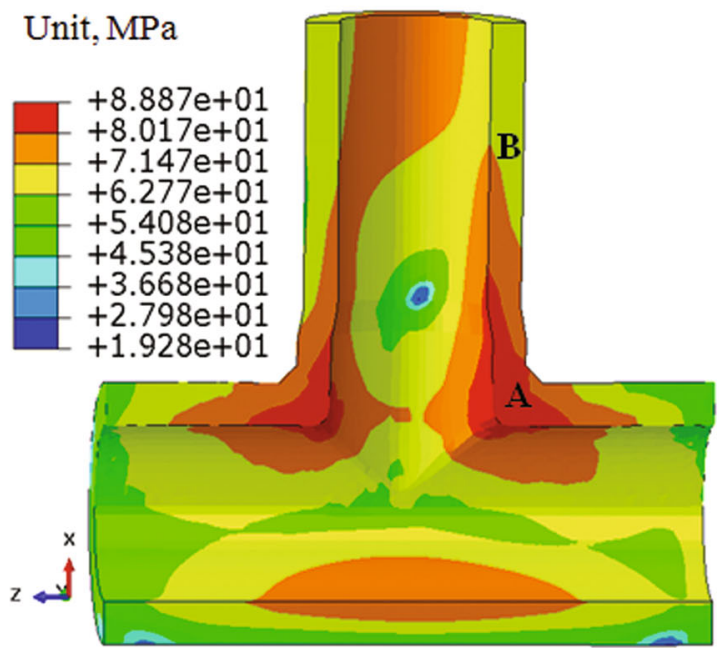

Fig. 1 Finite element analysis of operated stress in the T-junction: a size of the T-junction, b finite element mesh model, $\mathbf{c}$ load and boundary conditions, $\mathbf{d}$ counter plot of von Mises stress

Table 1 Chemical composition of different specimens in the tee (in wt $\%$ )

\begin{tabular}{llllllllllll}
\hline Specimen & $\mathrm{C}$ & $\mathrm{Si}$ & $\mathrm{Mn}$ & $\mathrm{V}$ & $\mathrm{Cr}$ & $\mathrm{Mo}$ & $\mathrm{Nb}$ & $\mathrm{S}$ & $\mathrm{P}$ & $\mathrm{N}$ & $\mathrm{Fe}$ \\
\hline $\mathrm{A}$ & 0.12 & 0.30 & 0.44 & 0.20 & 8.62 & 0.93 & 0.06 & 0.003 & 0.017 & 0.044 & Bal. \\
$\mathrm{B}$ & 0.11 & 0.27 & 0.43 & 0.21 & 8.41 & 0.92 & 0.06 & 0.003 & 0.017 & 0.047 & Bal. \\
\hline
\end{tabular}

$\mathrm{C}$ concentration. There are about $2.5 \mathrm{vol} \% M_{23} \mathrm{C}_{6}$ and 0.2 vol\% $M X$ after longtime aging, and the solid solution $\mathrm{C}$ atoms are exhausted to form carbides [17]. Therefore, the $\mathrm{C}$ concentration of matrix in the aged specimens could be considered as 0 . Thermo-Calc calculation result is also $1.38 \times 10^{-8} \mathrm{wt} \% \mathrm{C}$ in matrix, which is in good agreement with the calculated result according to volume fraction of precipitated carbides. With decreasing $\mathrm{C}$ concentration, there is a trend to form Laves phase. However, the formation of Laves phase is still a thermodynamically impossible process, even though $\mathrm{C}$ concentration of matrix is 0, as shown in Fig. 2a. Laves phase precipitates in the regions adjacent to $M_{23} \mathrm{C}_{6}$ particles or along the martensite packet or the grain boundaries. The reason for this is that such regions have relatively high content of Mo, due to the rearrangement of alloy-forming elements such as $\mathrm{Cr}$ and 

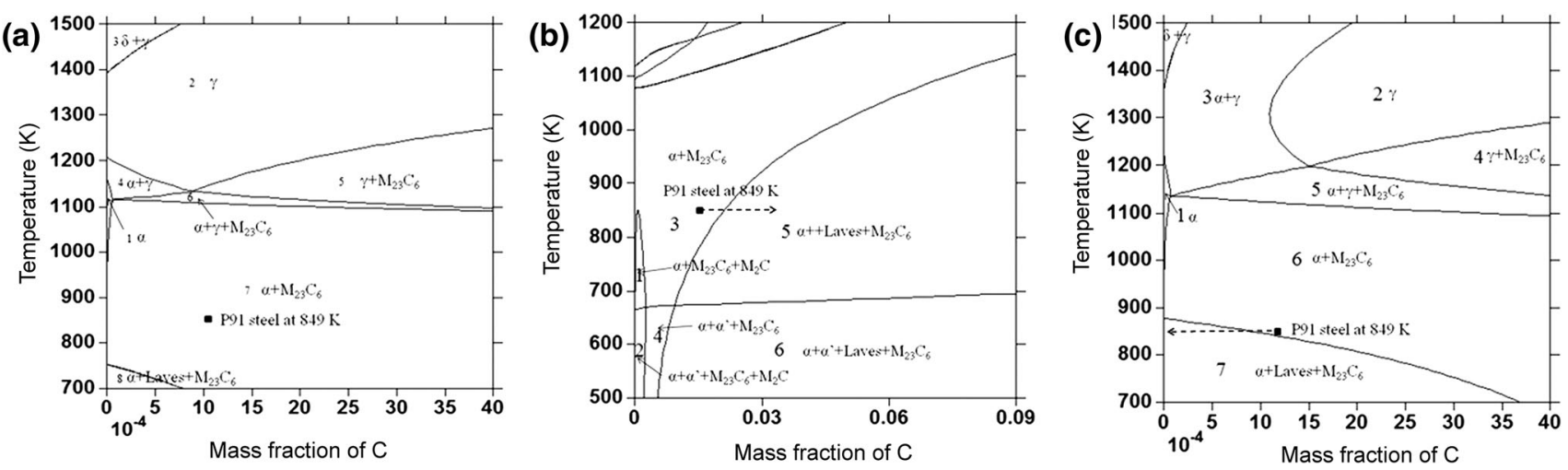

Fig. 2 Equilibrium phase diagrams of P91 steel calculated by Thermo-Calc software with database SSOL5: a 9Cr-1Mo, b Mo concentrationtemperature, $\mathbf{c} 9 \mathrm{Cr}-2 \mathrm{Mo}$

Mo in the vicinity of the Cr-rich $M_{23} \mathrm{C}_{6}$ carbides, $M_{23} \mathrm{C}_{6}$ carbide which pushes $\mathrm{Si}$ toward a micrograin boundary, or due to the grain boundary segregation of Mo and $\mathrm{Si}$ on martensite lath and packet boundaries [18, 19]. ThermoCalc calculations of the phase diagram for $9 \mathrm{Cr}$ steel are shown in Fig. 2b, which denotes that phases change with temperature and Mo concentration. With increasing Mo concentration, there is a trend to form Laves phase. Because the above regions have relatively high molybdenum content, Laves phase forms and reaches its equilibrium by diffusion of Mo. It is in good agreement with the report that Laves phase begins to precipitate in $9 \mathrm{Cr}-2 \mathrm{Mo}$ steel during aging at $873 \mathrm{~K}$ [18], and $M_{23} \mathrm{C}_{6}$ carbides are $\mathrm{Si}$ free, while Laves phase particles contain 9 at\% Si. This is in well agreement with our experimental results due to the combined segregation of Mo and Si from the matrix to the micrograin boundaries [19]. Decreasing the amount of carbon and increasing the amount of Mo promote the formation of Laves phase in Fig. 2c. Creep stress enhances the Laves phase formation in $\mathrm{Fe}-10 \mathrm{Cr}-6 \mathrm{~W}$ steel during the

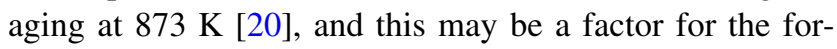
mation of Laves phase.

\subsection{Effect of Laves Phase on Mechanical Properties}

Mechanical properties including tensile strengths and impact toughness of the used pipe (the specimen A and B) show a decrease compared to the original pipe in Table 2 . The ultimate and yield tensile strength of the specimen $\mathrm{A}$ is lower than that of the specimen B at room and high temperature. Impact energy at longitude and transverse of the specimen $\mathrm{A}$ is much lower than that of the specimen $\mathrm{B}$.

The operated stress gradually decreases from inner wall to outer wall in the both specimens. However, there is an increase in impact toughness from inner wall to outer wall, as shown in Fig. 3. It could be inferred that the impact toughness decreases with increasing operated stress. The study has indicated that creep stress enhances the Laves phase formation during the aging at $873 \mathrm{~K}$ [21]. The mean size of Laves phase increases with increasing creep stress. Mechanical properties mainly depend on the mean size and volume fraction of the precipitates and the size of the martensitic packets in 9\% Cr heat-resistant steels [20]. Effects of the precipitates on the tensile and creep properties in these steels have been widely studied [22-24]. From the viewpoint of precipitation strengthening, the tensile strength reduces with coarsening of Laves phase. The precipitation of Laves phase will reduce creep strength, if Laves phase coarsens rapidly and is formed at the expense of an existing, finer particle or it leads to withdrawal of elements from solid solution. The ductilebrittle transition temperature rises and the impact energy decreases when Laves phase begins to precipitate during aging [18].

Table 2 Mechanical properties of the tee and original pipe

\begin{tabular}{llllllr}
\hline Specimen & $\begin{array}{l}\text { Yield strength } \\
(\mathrm{MPa})\end{array}$ & $\begin{array}{l}\text { Tensile strength } \\
(\mathrm{MPa})\end{array}$ & $\begin{array}{l}\text { Yield strength } \\
\text { at } 849 \mathrm{~K} \\
(\mathrm{MPa})\end{array}$ & $\begin{array}{l}\text { Tensile strength } \\
\text { at } 849 \mathrm{~K} \\
(\mathrm{MPa})\end{array}$ & $\begin{array}{l}\text { Impact energy } \\
\text { at longitude } \\
(\mathrm{J})\end{array}$ & $\begin{array}{l}\text { Impact energy } \\
\text { at transverse } \\
(\mathrm{J})\end{array}$ \\
\hline A & 380 & 610 & 240 & 290 & 35 & 23 \\
B & 450 & 650 & 290 & 320 & 91 & 212 \\
Original pipe & 505 & 660 & 335 & 370 & 165 \\
\hline
\end{tabular}




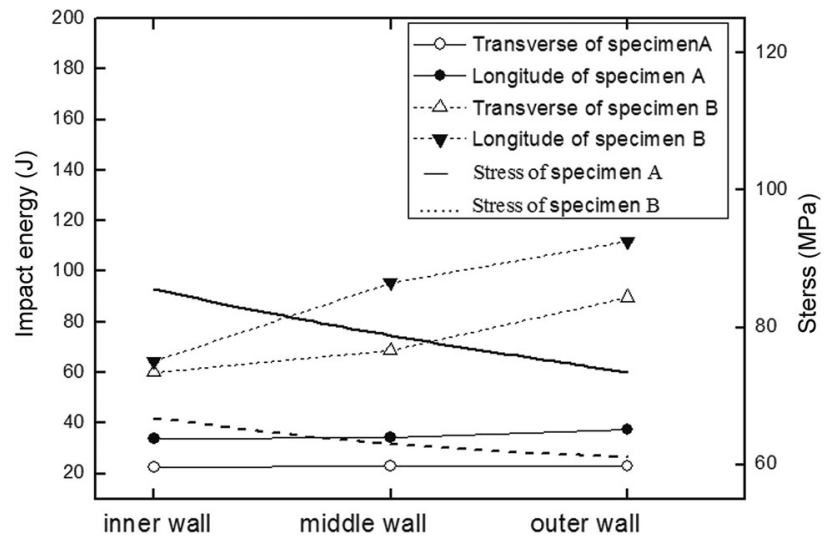

Fig. 3 Change in impact toughness and stress in the T-junction

Further to study impact toughness of the both specimens by instrumented impact testing machines, as shown in Table 3 and Fig. 4, the value comes from a typical one of the impact specimens. The crack initiation energy and the crack growth energy of the specimen A are lower than that of the specimen B, respectively. And the ratios of the crack initiation energy to impacting absorption energy at transverse and longitude in the specimen $\mathrm{A}$ are much greater than those of the specimen $\mathrm{B}$, and the crack will be easily developed in the specimen $\mathrm{A}$ if the crack forms at small impact energy. The results indicate that the effect of crack growth on impact absorbing energy is little for specimens A.

The microstructure of both specimens is fully martensite with similar equiaxed prior austenitic grain size (about $60 \mu \mathrm{m})$. The effect of inclusion on toughness is almost neglected for similar distribution and morphology of inclusion in one P91 steel tee. The microstructure observations give no evidence of difference for $M_{23} \mathrm{C}_{6}, M X$, lath width and dislocation density in the both specimens as shown in Fig. 5. The results indicate that the main difference of the precipitation behavior in the both specimens is the volume fraction and mean size of Laves phase. Laves phase particles with mean size of $(397 \pm 35) \mathrm{nm}$ are

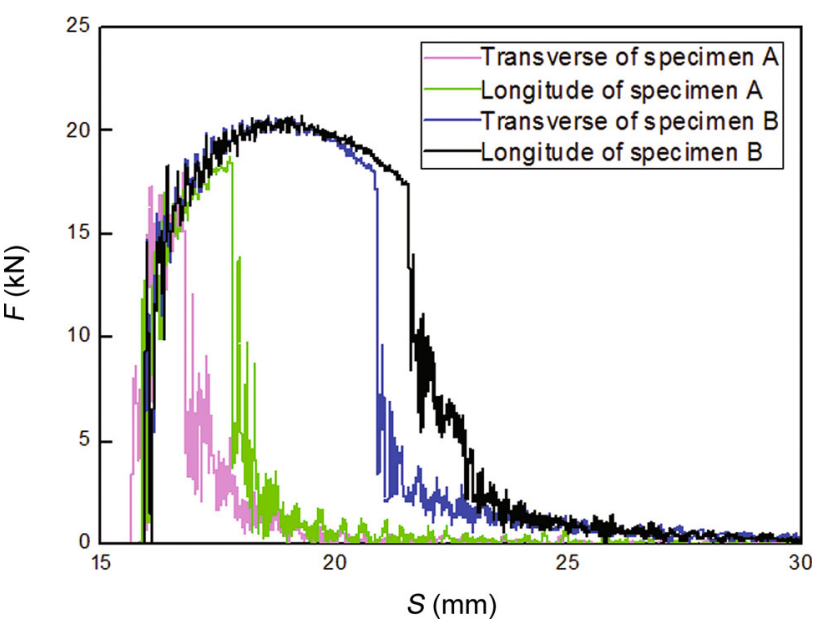

Fig. 4 Waveform graph of instrumented impact testing of both specimens

distributed mainly along the lath and the grain boundaries in the specimen $\mathrm{A}$, which is almost twice larger than that of the specimen $B(216 \pm 26) \mathrm{nm}$. Coarsening of Laves phase will be faster in the region with higher stress, and it brings out the rapid reduction in the tensile strength and impact energy.

Si plays a key role in the formation and growth of Laves particles. A general formula has been assumed [11], from which reaction describing the formation of laves phase is

$0.9 \mathrm{Fe}+0.6 \mathrm{Cr}+0.8 \mathrm{Mo}+0.7 \mathrm{Si}=[$ Laves $]$.

An increment of the $\mathrm{Si}$ content in tempered martensite/ferrite steel accelerates the precipitation of Laves phase in ferrite grains [20]. The precipitates with Mo and $\mathrm{Si}$ are denoted as $\mathrm{Fe}_{2} \mathrm{Mo}$ Laves phase in Fig. 6 and Table 4. Mo and Si enriched in Laves phase are a typical characterization as the formation of Laves phase.

The quantification of Laves phase in (9-12) wt\% $\mathrm{Cr}$ steels using a standard SEM is shown in Ref. [10]. Laves phase precipitates with volume fraction of $2.5 \%$ are along the lath and the packet boundaries in the specimen $\mathrm{A}$, but there are Laves phase precipitates with volume fraction of

Table 3 Impact absorbing energy during the process of the fracture in both specimens

\begin{tabular}{lll}
$\begin{array}{l}\text { Crack initiation energy } \\
(\mathrm{J})\end{array}$ & $\begin{array}{l}\text { Crack growth energy } \\
(\mathrm{J})\end{array}$ & $\begin{array}{l}\text { Ratio of the crack initiation } \\
\text { energy to impacting absorption energy } \\
(\%)\end{array}$ \\
\hline 13.5 & 8.5 & 61.4 \\
28.7 & 5.5 & 83.2 \\
45.7 & 49.6 & 47.9 \\
59.9 & 51.8 & 53.6 \\
\hline
\end{tabular}



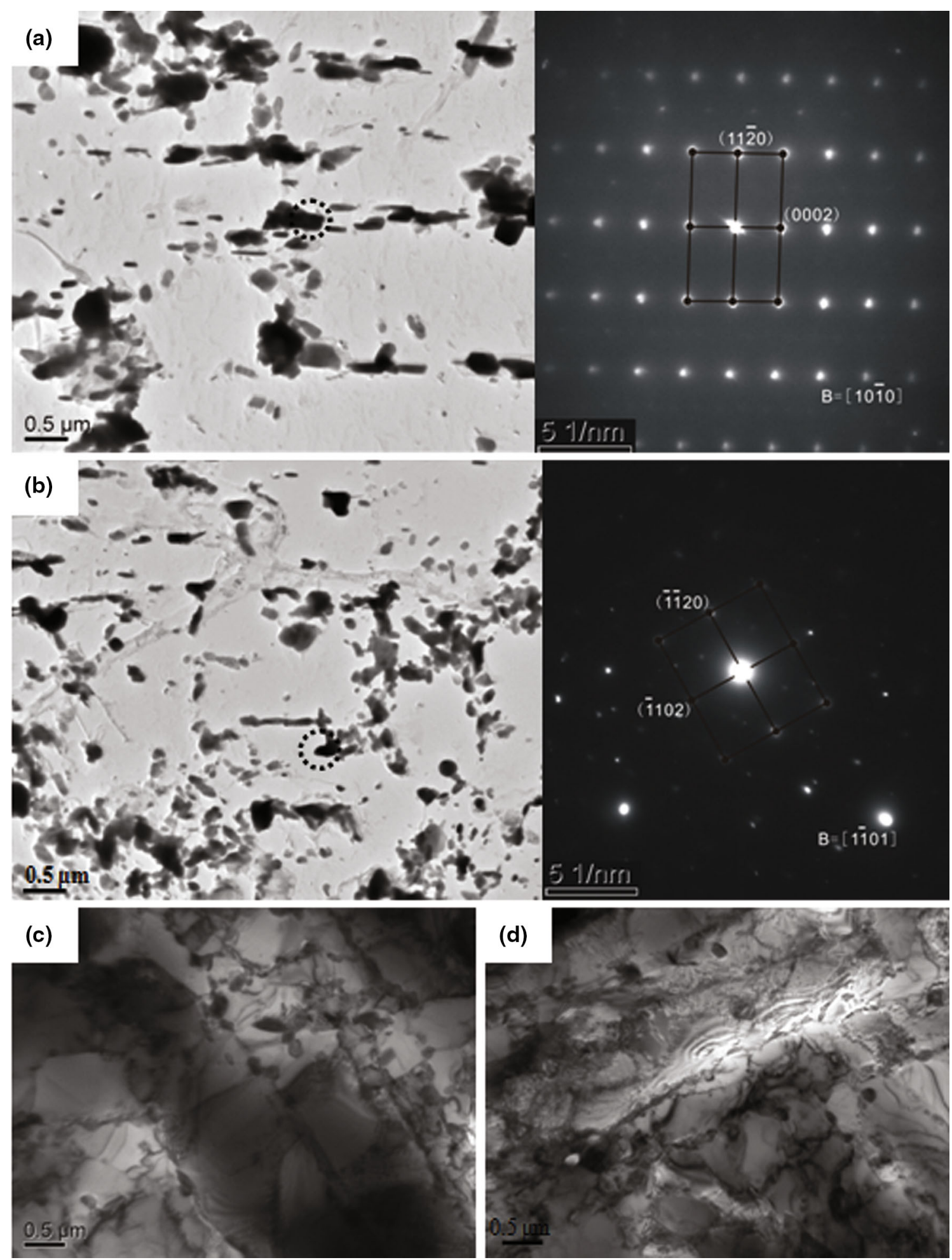

Fig. 5 Microstructure and distribution of the precipitations in both steels: a, c specimen A; b, d specimen B

$1.3 \%$ along the grain and packet boundaries in the specimen B as shown in Fig. 6.

The main crack proceeds by coalescence of small voids initiated by precipitates, resulting in the final fracture of the specimen [25]. Therefore, the decrease in the impact toughness in both specimens depends on the coarse Laves phase. As shown in Fig. 7, the crack proceeds by coalescence of small voids initiated at Laves phase and carbides 

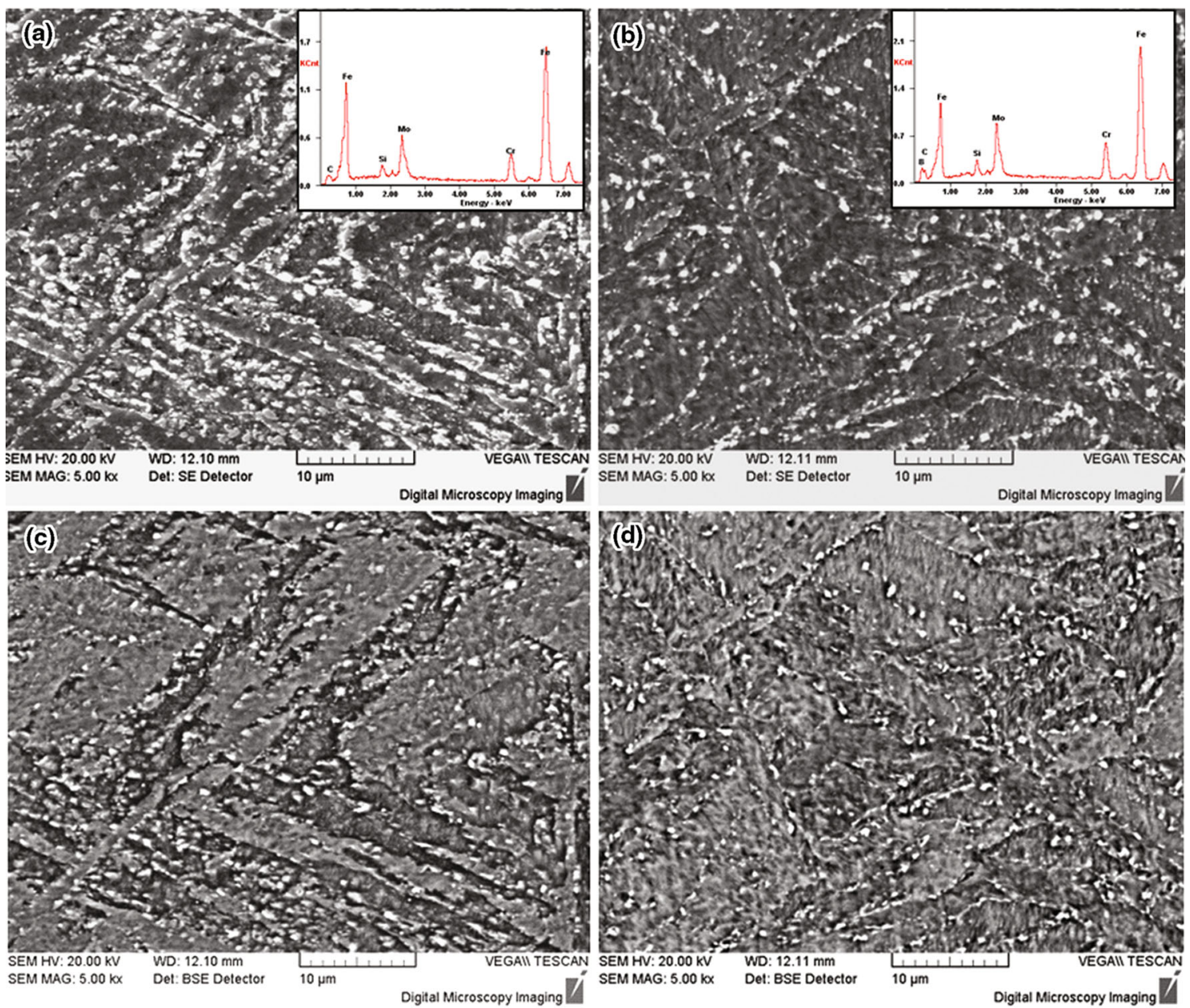

Fig. 6 Secondary electron images and backscattered electron images of both specimens: a, c specimen A; b, d specimen B

Table 4 Chemical composition of different specimens in different phases (wt $\%)$

\begin{tabular}{llllrrl}
\hline Specimen & Phases & $\mathrm{C}$ & $\mathrm{Si}$ & $\mathrm{Cr}$ & \multicolumn{1}{c}{$\mathrm{Mo}$} & $\mathrm{Fe}$ \\
\hline A & Laves & - & 3.17 & 10.45 & 41.28 & 45.1 \\
& $M_{23} \mathrm{C}_{6}$ & 8.86 & - & 59.57 & 6.92 & 24.65 \\
B & Laves & - & 3.22 & 9.91 & 41.75 & 45.12 \\
& $M_{23} \mathrm{C}_{6}$ & 6.26 & - & 52.32 & 8.01 & 33.41 \\
Thermo-Calc & Laves & - & - & 1.19 & 45.45 & 53.36 \\
& $M_{23} \mathrm{C}_{6}$ & 5.14 & - & 70.82 & 20.40 & 3.64 \\
\hline
\end{tabular}

particles, and crack extension proceeds by the fibrous mode and the growth of voids at the particles site. The precipitates with the large mean size and volume fraction in the specimen A make development of a shear band be easier than that of the specimen B. The main crack proceeds by rupture through localized shear of the internal ligaments, and the impact toughness of the specimen A becomes worse. So the impact toughness of the specimen A is lower than that of the specimen $\mathrm{B}$.

\section{Conclusions}

1. The formation of Laves phase in P91 steel is a thermodynamically possible process due to enrichment of Mo and depletion of $\mathrm{C}$ adjacent to $M_{23} \mathrm{C}_{6}$ particles or along the martensite lath and packet boundaries. Decreasing the amount of carbon and increasing the amount of Mo would promote the formation of Laves phase.

2. The maximum operated stress happens to the shoulder of T-junction von Mises stress from inner wall to outer wall gradually decreased in P91 steel T-junction under 25.65 MPa vapor pressure.

3. A number of $\mathrm{Fe}_{2} \mathrm{Mo}$ Laves phase precipitates have been found in the P91 steel T-junction at $849 \mathrm{~K}$ for $58,000 \mathrm{~h}$. Mo and $\mathrm{Si}$ enriched in Laves phase are a 

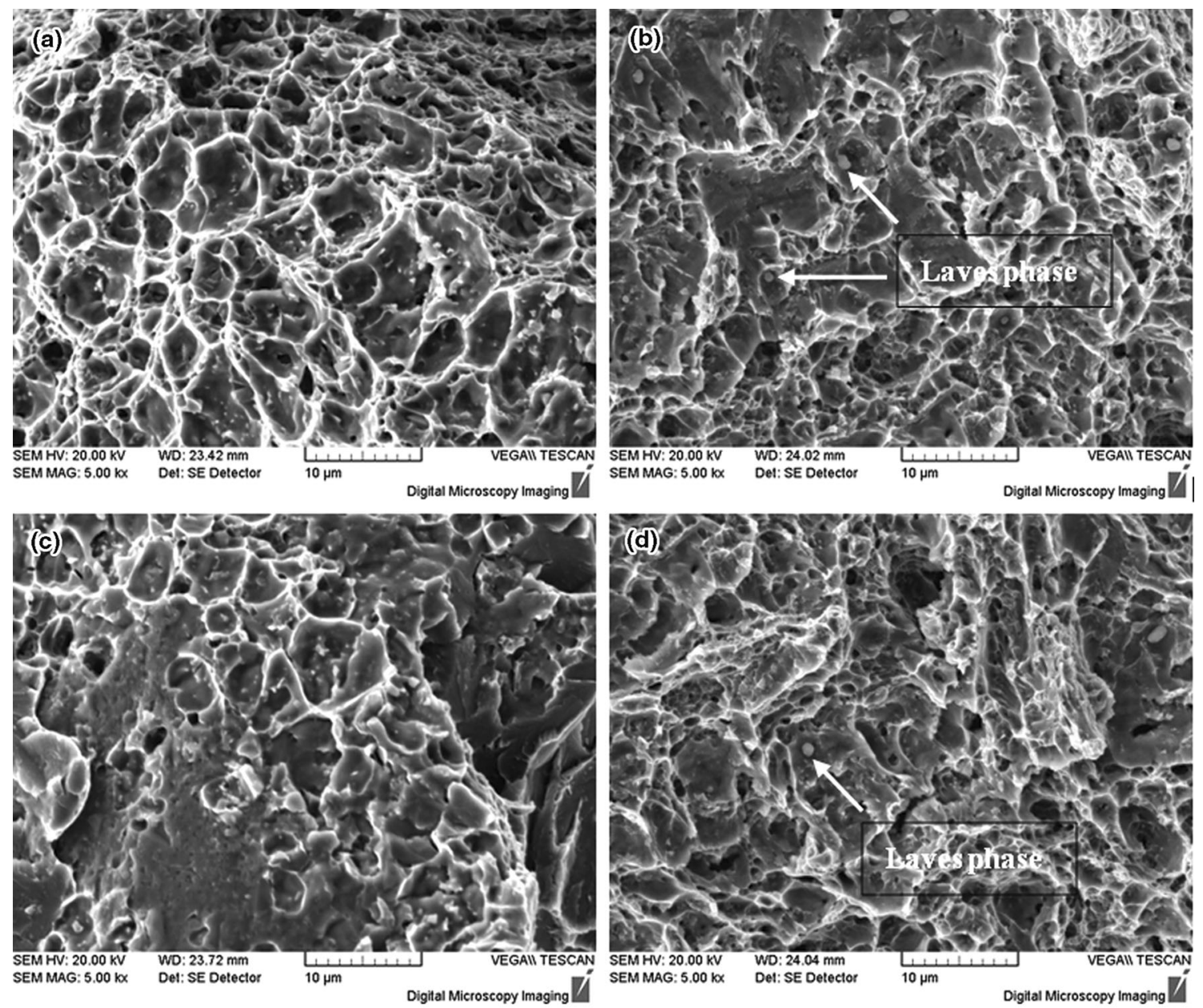

Fig. 7 SEM images of impact fracture surfaces in the both specimens: a crack initiation zone and c crack growth zone in the specimen A; b crack initiation zone and $\mathbf{d}$ crack growth zone in the specimen B

typical characterization as the formation of Laves phase. The growth of Laves phase would be accelerated by operated stress, and it brings out the reduction in tensile properties and impact energy.

4. The formation of Laves phase has a dramatic influence on the mechanical properties in P91 steel. The detrimental effect of Laves phase on the tensile properties and the impact toughness mainly depends on the volume fraction and mean size of Laves phase in P91 steel. With increasing the mean size and volume fraction of Laves phase, the crack initiation energy and the crack growth energy would rapidly decrease.

Acknowledgments This work was financially supported by the National Natural Science Foundation of China (Nos. 51201061, 51475315), China Postdoctoral Science Foundation (No. 2015M571804) and the Natural Science Foundation of Jiangsu Province (No. SBK2015040170). The authors thank Dr. Zenan Yang for discussion.

\section{References}

[1] F. Abe, Mater. Sci. Eng., A 319, 770 (2001)

[2] P.J. Ennis, A. Zielinska-Lipec, O. Wachter, A. Czyrska-Filemonowicz, Acta Mater. 45, 4901 (1997)

[3] F. Abe, H. Araki, T. Noda, Metall. Trans. A 22, 2225 (1991)

[4] Z.X. Xia, C. Zhang, H. Lan, Z.G. Yang, P.H. Wang, J.M. Chen, Mater. Sci. Eng., A 528, 657 (2010)

[5] O. Prat, J. Garcia, D. Rojas, G. Sauthoff, G. Inden, Intermetallics 32, 362 (2013)

[6] A. Mahmoudi, M.R. Zamanzad Ghavidel, S. Hossein Nedjad, A. Heidarzadeh, M. Nili Ahmadabadi, Mater. Charact. 62, 976 (2011)

[7] A. Kipelova, A. Belyakov, R. Kaibyshev, Mater. Sci. Eng., A 532, 71 (2012)

[8] J.S. Lee, H.G. Armaki, K. Maruyama, H. Asahi, Mater. Sci. Eng., A 428, 270 (2006)

[9] V. Knezevic, G. Sauthoff, J. Vilk, G. Inden, A. Schneider, R. Agamennone, ISIJ Int. 12, 1505 (2002)

[10] G. Dimmlera, P. Weinert, E. Kozeschnik, H. Cerjak, Mater. Charact. 51, 341 (2003)

[11] B.A. Senior, Mater. Sci. Eng., A 119, 5 (1989) 
[12] P.J. Ennis, C. Filemonowicz, Sadhana 28, 709 (2003)

[13] Y. Tsuchida, K. Okamoto, Y. Tokunaga, ISIJ Int. 35, 317 (1995)

[14] H.J. Zhang, S.T. Liu, C.X. Fan, Electr. Power 40, 12 (2007)

[15] J.H. Baek, S.H. Kim, C.B. Lee, D.H. Hahn, Met. Mater. Int. 15, $565(2009)$

[16] W.S. Ryu, S.H. Kim, Trans. Indian Inst. Met. 63, 111 (2010)

[17] Z.X. Xia, C. Zhang, Z.G. Yang, Mater. Sci. Eng., A 528, 6764 (2011)

[18] Y. Hosoi, N. Wade, S. Kunimitsu, T. Urita, J. Nucl. Mater. 141, 461 (1986)

[19] M.I. Isik, A. Kostka, V.A. Yardley, K.G. Pradeep, M.J. Duarte, P.P. Choi, D. Raabe, G. Eggeler, Acta Mater. 90, 94 (2015)
[20] Z.X. Xia, C. Zhang, Z.Y. Yang, Mater. Sci. Technol. 27, 282 (2011)

[21] J. Cui, I.S. Kim, C.Y. Kang, K. Miyahara, ISIJ Int. 41, 368 (2001)

[22] F.R. Larson, J. Miller, Trans. ASME 74, 756 (1952)

[23] R.L. Orr, O.D. Sherby, J.E. Dorn, Trans. ASM 46, 113 (1954)

[24] Z.X. Xia, C. Zhang, N.Q. Fan, Y.F. Zhao, F. Xue, S.J. Liu, Mater. Sci. Eng., A 545, 91 (2012)

[25] Y. Tomita, J. Mater. Sci. 26, 35 (1991) 